\title{
Changes of Bile Acids and Energy Expenditure after Laparoscopic Cholecystectomy in type 2 Diabetes Patients: A Prospective Study
}

\section{Haixin Yin}

Peking Union Medical College Hospital

\section{Weijie Chen}

Peking Union Medical College Hospital

\section{Liangbo Dong}

Peking Union Medical College Hospital

\section{Shengnan Zhou}

Peking Union Medical College Hospital

\section{Qiang Qu}

Peking Union Medical College Hospital

\section{Ning Zhang}

Peking Union Medical College Hospital

Xiaodong He ( $\sim$ hxdpumch@163.com )

Peking Union Medical College Hospital https://orcid.org/0000-0002-6682-2926

\section{Research article}

Keywords: Cholecystectomy, Total Bile Acids, Type 2 Diabetes, Energy, Metabolism

Posted Date: January 20th, 2021

DOl: https://doi.org/10.21203/rs.3.rs-150355/v1

License: (a) (1) This work is licensed under a Creative Commons Attribution 4.0 International License. Read Full License 


\section{Abstract}

Background and aims: Our aims were to investigate changes of bile acids and resting energy expenditure (REE) in patients with type 2 diabetes mellitus (T2DM) after laparoscopic cholecystectomy (LC) and the role in metabolic homeostasis.

Methods: From December 2019 to May 2020, a total of 77 T2DM patients with gallbladder polyps were included in our study. Among them, 40 patients who underwent LC were enrolled into cholecystectomy group, 37 patients who did not undergo LC were enrolled into control group. Preoperative and 6-months postoperative demographic data, body weight, food intake, effects on diabetes control, and biomedical variables were recorded and compared.

Results: The mean level of total bile acids (TBA) was higher than that in control group ( $P=0.033)$ and increased significantly after LC compared to baseline $(P=0.029)$. The resting energy expenditure (REE) level in cholecystectomy group was higher than that in control group $(P=0.032)$ and increased compared to the baseline $(P=0.011)$. The utilization of carbohydrate increased significantly after $L C(P<0.001)$ while the utilization of fat decreased $(P<0.001)$. The mean level of FPG $(P=0.004), \mathrm{A} 1 \mathrm{C}(P<0.001)$ and HOMA-IR $(P=0.045)$ decreased after $L C$, as defined, the total effectiveness rate was $45 \%$. The mean level of total cholesterol $(P=0.003)$ and low-density lipoprotein cholesterol significantly decreased $(P=0.021)$, whereas the level of high-density lipoprotein cholesterol increased $(P<0.001)$.

Conclusions: The level of REE and TBA increased after LC in patients with T2DM, the glucose and lipid metabolism improved.

Trial registration: Chinese Clinical Trial Registry, ChiCTR1900027823. Registered 30 November 2019, http://www.chictr.org.cn/index.aspx.

\section{Background}

Type 2 diabetes mellitus (T2DM) is currently a global health crisis that leads to a decrease in quality of life for patients and a heavy economic burden on society [1, 2]. Over decades, researchers have devoted to explore the pathogenesis of diabetes, looked for effective predictors and ways to improve diabetes and its complications. While T2DM is a complex whole-body metabolic abnormality, macroscopically involving age, obesity, diets, and lifestyle, also genetic architecture, signaling pathways, inflammation, endothelial dysfunction and iron overload in microscopic [3]. To date, there is not a single approach to cure or even remit diabetes, a "cocktail therapy" is still the mainstream treatment. Therefore, a whole and in-depth understanding of pathogenesis and metabolic characteristics in diabetes is conductive to develop effective treatment based on the evidence.

Laparoscopic cholecystectomy $(\mathrm{LC})$ is the commonly performed procedure for the surgical treatment of patients with gallbladder disease [4]. Currently, gallbladder is not considered just as a storage of bile, previous studies suggested that gallbladder removal can lead to numerous metabolic changes $[5,6]$. 
Studies reported bile acids (BAs) level increased after cholecystectomy in mice [7, 8], and circulated faster by continuously secreting into duodenum [9], thereby increased basal metabolic rate through G-protein coupled bile acids receptor dependent mechanisms. A study in human also showed resting energy expenditure (REE) increased after LC [10]. Increased energy expenditure may decrease the glucose level since blood glucose is the main source of energy in the body. While this human study was a short-term study (within 3 postoperative days), the results were inevitably affected by the post-operative stress response and inflammation. Moreover, studies also showed that BAs level remained unchanged after cholecystectomy $[9,11]$, or decreased [12] maybe due to the increased bile loss in feces [13]. Therefore, the changes of BAs after cholecystectomy was still controversial and the REE in long-term effects remain unclear, and these changes in patients with T2DM have been even less reported. Our aims were to investigate the long-term effects of LC on TBA and REE in patients with T2DM and the role in metabolic homeostasis.

\section{Patients And Methods}

\section{Patients}

This study included T2DM patients with asymptomatic gallbladder polyps in the department of general surgery at Peking Union Medical College Hospital (PUMCH, Beijing, China) from December 2019 to May 2020. Patients who underwent LC because of the polyps larger than $1 \mathrm{~cm}$ were enrolled into the experimental group. During the same period, T2DM patients in outpatient service without indications of gallbladder polyps matched for gender, age, and body mass index (BMI) were enrolled into the control group. T2DM was diagnosed according to guidelines from the American Diabetes Association: 1) fasting plasma glucose (FPG) $\geq 7 \mathrm{mmol} / \mathrm{L}(126 \mathrm{mg} / \mathrm{dL})$; or 2) random plasma glucose $\geq 11.1 \mathrm{mmol} / \mathrm{l}$ (200 mg/dl); or 3) 2-h plasma glucose $\geq 11.1 \mathrm{mmol} / \mathrm{L}(200 \mathrm{mg} / \mathrm{dL})$ during an oral glucose tolerating test; or 4$)$ hemoglobin $\mathrm{A} 1 \mathrm{C}(\mathrm{A} 1 \mathrm{C}) \geq 6.5 \%(48 \mathrm{mmol} / \mathrm{mol})[14]$.

Cholecystolithiasis patients who underwent LC were excluded because there is an association between gallstone disease and metabolic syndromes [15] and the inflammation involved in cholecystitis might affect glucose metabolism [16]. Other exclusion criteria were as follows: (1) coexisting malignant diseases; (2) gallbladder polyps confirmed as malignant; (3) complications such as fistula, bile duct injury, and infection; (4) debilitating disease, unresolved psychiatric illness, pregnancy or substance abuse, which might affect metabolism and follow-up work; (5) lipid-lowering agents or changing dietary habits after surgery; (6) patients who dropped out of the study.

This study adhered to CONSORT guidelines and was approved by the Ethics Committee of PUMCH at the Chinese Academy of Medical Sciences and Peking Union Medical College, and registered in Chinese Clinical Trial Registry, registered number: ChiCTR1900027823. Informed consents were obtained after detailed explanation of the study.

\section{Methods}


Preoperative and 6-months postoperative data regarding sex, age, height (to within $0.1 \mathrm{~cm}$ ), body weight (to within $0.1 \mathrm{~kg}$ ), BMl, food intake, comorbidities, operation details, and diabetes mellitus, including disease duration and medication use, were recorded and analyzed. The change in food intake amount was assessed using the 2005 Block Food Frequency Questionnaire, which has been used in numerous previous weight-loss intervention trials, including the Diabetes Prevention Program [17].

\section{Resting energy expenditure}

The REE and energy substrate consumption were measured with a CMA (COSMED Quark PFT Ergo, Italy). After overnight fasting, the patients were tested in an ambient temperature of 25 degrees centigrade. The patient lied flat on the test bed without any activity, after 5 minutes of adaptation, the oxygen consumption and carbon dioxide output were obtained from a shield covering the head, thereby the REE was calculated. The whole procedure took approximately 20 minutes.

\section{Biomedical parameters}

Biomedical parameters obtained included total bile acids (TBA), FPG, A1C, insulin, c-peptide, total cholesterol (TC), triglyceride (TG), high-density lipoprotein cholesterol (HDL-C), and low-density lipoprotein cholesterol (LDL-C) levels. The homeostasis model assessment-insulin resistance (HOMA-IR) was calculated using the formulas: HOMA-IR $=$ FPG $(\mathrm{mmol} / \mathrm{L}) \times$ insulin $(\mathrm{mlU} / \mathrm{ml}) / 22.5$, homeostasis model assessment - beta cell function (HOMA- $\beta$ ) was calculated as follow: HOMA- $\beta=20 \times$ insulin $(\mathrm{mlU} / \mathrm{ml}) /$ [FPG (mmol/L) - 3.5] [18].

\section{Definition of remission in T2DM}

Patients who had A1C of $<6.0 \%$ without diabetic medication was defined to "in remission", patients who had $\mathrm{A} 1 \mathrm{C}$ of $<6.0 \%$ with a reduction of antidiabetic medication was defined to "improved", patients with an A1C concentration $>6.0 \%$ or without a reduction of antidiabetic medication was defined to "unimproved". The total effectiveness rate of the treatment was calculated as the sum of the rates of "in remission" and "improved" cases $[18,19]$.

\section{Statistical analysis}

We conducted statistical analysis using SPSS Statistics software (version 24.0, IBM, USA) and drafted histograms using the GraphPad software (version 7.0, GraphPad Prism, USA). Quantitative data are shown as the mean \pm standard deviation, and differences in continuous variables before and after surgery were assessed by paired t-tests. The unpaired t-test and chi-square test were used to compare each variable between cholecystectomy and control group. All statistics were 2 tailed, and $P$ values less than 0.05 were considered statistically significant.

\section{Results}

\section{Patients}


From December 2019 to May 2020, a total of 77 T2DM patients were included in this study, 40 of them were underwent surgical treatment and enrolled into the cholecystectomy group, and 37 patients without surgical indications were enrolled into the control group. The preoperative clinical characteristics of both groups in age, sex, BMl, duration of diabetes and other biochemical indicators were compared in Table 1. There were no subjects dropped out over the course of the study. 
Table 1

Baseline characteristics of the enrolled patients with type 2 diabetes in both groups.

\begin{tabular}{|c|c|c|c|}
\hline Characteristics & $\begin{array}{l}\text { Cholecystectomy } \\
(n=40)\end{array}$ & $\begin{array}{l}\text { Control } \\
(n=37)\end{array}$ & $p$ value \\
\hline Age (years) & $55.9 \pm 14.4$ & $51.2 \pm 12.0$ & 0.125 \\
\hline Male/Female (n) & $17 / 23$ & $19 / 18$ & 0.583 \\
\hline BMI $\left(\mathrm{kg} / \mathrm{m}^{2}\right)$ & $24.4 \pm 3.3$ & $25.2 \pm 3.0$ & 0.287 \\
\hline Food intake (kcal) & $1925.4 \pm 458.2$ & $2015.3 \pm 369.1$ & 0.349 \\
\hline Duration of diabetes (month) & $20.9 \pm 12.9$ & $19.9 \pm 13.6$ & 0.726 \\
\hline $\mathrm{TBA}(\mu \mathrm{mol} / \mathrm{L})$ & $3.3 \pm 2.2$ & $3.3 \pm 2.9$ & 0.987 \\
\hline REE (kcal) & $1292.0 \pm 260.4$ & $1353.0 \pm 315.6$ & 0.356 \\
\hline FAT $(\%)$ & $57.0 \pm 19.0$ & $54.2 \pm 19.8$ & 0.530 \\
\hline $\mathrm{CHO}(\%)$ & $43.5 \pm 18.9$ & $46.3 \pm 19.8$ & 0.522 \\
\hline $\mathrm{FPG}(\mathrm{mmol} / \mathrm{L})$ & $5.7 \pm 1.4$ & $5.6 \pm 1.4$ & 0.891 \\
\hline \multirow[t]{2}{*}{$\mathrm{A} 1 \mathrm{C}(\%, \mathrm{mmol} / \mathrm{mol})$} & $6.0 \pm 1.2$ & $6.0 \pm 1.3$ & \multirow[t]{2}{*}{0.935} \\
\hline & $(42.2 \pm 11.1)$ & $(41.9 \pm 13.2)$ & \\
\hline Insulin (ulU/ml) & $10.0 \pm 4.9$ & $10.3 \pm 5.9$ & 0.831 \\
\hline C-peptide (ng/ml) & $1.5 \pm 0.6$ & $1.6 \pm 0.7$ & 0.855 \\
\hline HOMA-IR & $2.5 \pm 1.6$ & $3.1 \pm 2.2$ & 0.179 \\
\hline HOMA- $\beta$ & $124.5 \pm 92.8$ & $123.6 \pm 58.9$ & 0.960 \\
\hline $\mathrm{TC}(\mathrm{mmol} / \mathrm{L})$ & $4.8 \pm 1.0$ & $4.7 \pm 0.9$ & 0.722 \\
\hline TG (mmol/L) & $1.4 \pm 0.7$ & $1.5 \pm 0.8$ & 0.651 \\
\hline HDL-C (mmol/L) & $1.2 \pm 0.3$ & $1.1 \pm 0.2$ & 0.066 \\
\hline LDL-C (mmol/L) & $3.0 \pm 1.0$ & $3.0 \pm 0.8$ & 0.816 \\
\hline \multicolumn{4}{|l|}{ Anti-diabetic medicine } \\
\hline Insulin/OHA (n) & $17 / 23$ & $15 / 22$ & 0.862 \\
\hline \multicolumn{4}{|c|}{$\begin{array}{l}\text { BMI, body mass index; FPG, fasting plasma glucose; } \mathrm{A} 1 \mathrm{C} \text {, hemoglobin A1c; TC, total cholesterol; TG } \\
\text { triglyceride; HDL-C, high-density lipoprotein cholesterol; LDL-C, low density lipoprotein cholesterol; } \\
\text { TBA, total bile acid; HOMA-IR, homeostasis model assessment-insulin resistance; HOMA- } \beta \text {, } \\
\text { homeostasis model assessment - beta cell function; OHA, oral hypoglycemic agents; REE, resting } \\
\text { energy expenditure; CHO, carbohydrate. Data are shown as the mean } \pm \text { SD.* indicates } P<0.05 \text {, ** } \\
\text { indicates } P<0.01 \text {, compared between the two preoperative groups. }\end{array}$} \\
\hline
\end{tabular}




\section{Operation details}

All included patients in cholecystectomy group were admitted to the hospital and successfully underwent LC without postoperative complications. The postoperative pathological results verified that all specimens were benign polyps, including 33 cases with single polyps and 7 cases with multiple polyps. The duration of the operation was $22.6 \pm 10.6 \mathrm{~min}$, intraoperative blood loss was $45.4 \pm 17.6 \mathrm{ml}$, and the duration of hospital stay was $2.6 \pm 0.9$ days. All patients were followed up for at least 6 months.

\section{Bodyweight and food intake}

There was no significant difference in BMI between groups at the baseline and 6 months after surgery. Food intake was estimated by questionnaires or telephone interviews, and the composition did not change much at 6 months after surgery. The daily food intake amounts also did not change much at baseline and 6 months after surgery (Table 1, Table 2). 
Table 2

Comparation of variables between groups at 6 months after surgery.

\begin{tabular}{|c|c|c|c|}
\hline Variable & $\begin{array}{l}\text { Cholecystectomy } \\
(\mathrm{n}=40)\end{array}$ & $\begin{array}{l}\text { Control } \\
(n=37)\end{array}$ & $P$ \\
\hline Total effectiveness (n, \%) & $18(45.0)$ & $0(0.0)$ & $<0.001 * *$ \\
\hline $\mathrm{BMI}\left(\mathrm{kg} / \mathrm{m}^{2}\right)$ & $24.4 \pm 3.3$ & $25.2 \pm 3.1$ & 0.309 \\
\hline Food intake (kcal) & $1862.7 \pm 358.2$ & $1988.7 \pm 476.5$ & 0.192 \\
\hline TBA $(\mu \mathrm{mol} / \mathrm{L})$ & $4.3 \pm 3.0$ & $3.1 \pm 1.9$ & $0.033^{*}$ \\
\hline REE (kcal) & $1430.0 \pm 257.5$ & $1291.3 \pm 298.6$ & $0.032^{*}$ \\
\hline FAT $(\%)$ & $39.8 \pm 21.1$ & $49.9 \pm 19.5$ & $0.032^{*}$ \\
\hline $\mathrm{CHO}(\%)$ & $60.5 \pm 20.9$ & $50.6 \pm 19.4$ & $0.036^{*}$ \\
\hline FPG $(\mathrm{mmol} / \mathrm{L})$ & $4.9 \pm 1.0$ & $5.3 \pm 0.7$ & $0.047^{*}$ \\
\hline $\mathrm{A} 1 \mathrm{C}(\%, \mathrm{mmol} / \mathrm{mol})$ & $\begin{array}{l}5.2 \pm 0.7 \\
(32.8 \pm 7.6)\end{array}$ & $\begin{array}{l}5.6 \pm 0.6 \\
(37.3 \pm 6.9)\end{array}$ & $0.008 * *$ \\
\hline Insulin ( $\mu \mid \mathrm{IU} / \mathrm{mL})$ & $8.0 \pm 4.3$ & $9.8 \pm 5.7$ & 0.130 \\
\hline C-Peptide (ng/mL) & $1.5 \pm 0.6$ & $1.5 \pm 0.5$ & 0.701 \\
\hline HOMA-IR & $2.0 \pm 1.3$ & $2.6 \pm 1.5$ & $0.043^{*}$ \\
\hline HOMA- $\beta$ & $99.8 \pm 77.1$ & $126.5 \pm 74.4$ & 0.126 \\
\hline $\mathrm{TC}(\mathrm{mmol} / \mathrm{L})$ & $4.3 \pm 0.9$ & $4.7 \pm 0.9$ & $0.043^{*}$ \\
\hline $\mathrm{TG}(\mathrm{mmol} / \mathrm{L})$ & $1.4 \pm 0.8$ & $1.6 \pm 0.9$ & 0.474 \\
\hline HDL-C (mmol/L) & $1.8 \pm 0.3$ & $1.2 \pm 0.3$ & $<0.001$ ** \\
\hline LDL-C (mmol/L) & $2.6 \pm 0.9$ & $2.8 \pm 0.8$ & 0.221 \\
\hline \multicolumn{4}{|c|}{$\begin{array}{l}\text { BMI, body mass index; FPG, fasting plasma glucose; } A 1 C \text {, hemoglobin A1c; TC, total cholesterol; TG, } \\
\text { triglyceride; HDL-C, high-density lipoprotein cholesterol; LDL-C, low density lipoprotein cholesterol; } \\
\text { TBA, total bile acid; HOMA-IR, homeostasis model assessment-insulin resistance; HOMA- } \beta \text {, } \\
\text { homeostasis model assessment - beta cell function; REE, resting energy expenditure; CHO, } \\
\text { carbohydrate. Data are shown as the mean } \pm \text { SD.* indicates } P<0.05 \text {; ** indicates } P<0.01 \text {, compared } \\
\text { between the two postoperative groups. }\end{array}$} \\
\hline
\end{tabular}

\section{Changes of TBA}

The mean level of TBA was higher than that in control group $(P=0.033)$, and it was increased significantly 6 months after LC compared to the baseline $(P=0.029)$ (Fig. 1A).

\section{Effect on energy metabolism}


The REE level in cholecystectomy group was higher than that in control group at 6 months after LC $(P=$ 0.032 ) and increased significantly compared to the baseline $(P=0.011)$ (Fig. 1B). Carbohydrate and fat, the main sources of the body energy, showed opposite changes. The utilization of fat in cholecystectomy group was lower than that in control group $(P=0.032)$ and decreased compared to baseline $(P<0.001)$ (Fig. $1 \mathrm{H})$, while the utilization of carbohydrate was higher in cholecystectomy group $(P=0.036)$ and increased significantly compared to baseline $(P<0.001)$ (Fig. 1C).

\section{Effect on glucose metabolism}

Glucose metabolism in T2DM patients improved after LC. According to the definitions, 5 patients (12.5\%) were "in remission", 13 (32.5\%) were at an "improved" status 6 months after surgery. The total effectiveness rate was 45\% (FIG 1D). While the dosage of antidiabetic drugs used in control group did not change.

The biomedical indicators compared between groups after surgery were showing in Table 2. The mean level of FPG was lower than that in control group 6 months after surgery $(P=0.047)$ and decreased compared to the baseline $(P=0.004)$ (Fig. 1E). The A1C level was also lower compared to the baseline $(P$ $<0.001)$ (Fig. 1F) and control group $(P=0.008)$. Additionally, the average value of HOMA-IR was lower than that in control group $(P=0.043)$ and baseline $(P=0.045)$ (Fig. 1G). There was no significant difference in the HOMA- $\beta$ value compared to the baseline $(P=0.059)$ and control group $(P=0.126)$.

\section{Effect on lipid metabolism}

The metabolic changes of lipid after LC was showing in Fig. 1H. The mean level of TC was lower than that in control group $(P=0.043)$ and significantly decreased in cholecystectomy group at 6 months after surgery $(P=0.003)$, LDL-C level decreased compared to the baseline at 6 months after surgery $(P=0.021)$. While the average level of HDL-C was higher than that in control group $(P<0.001)$ and increased significantly compared to the baseline $(P<0.001)$. There was no significant difference in the TG level compared to the baseline $(P=0.924)$ and control group $(P=0.474)$.

\section{Discussion}

This study showed that the REE increased significantly after LC in patients with T2DM, and the utilization of carbohydrate elevated while that of fat decreased. And the glucose and lipid metabolism improved with the increased TBA level.

BAs played an important role in the elimination of cholesterol and the absorption of vitamins and fats [20]. It was synthesized from cholesterol in the liver, accounting for catabolism of approximately $50 \%$ of the daily cholesterol output. BAs are stored in gallbladder and secreted into the intestine when a meal is ingested, yet $95 \%$ of BAs are reabsorbed and transported back to the liver via the portal vein, escaped BAs were converted to secondary BAs by intestinal microbiota and excreted in the feces. This system is known as enterohepatic circulation [21]. The rhythmic filling and emptying of gallbladder control the flow of bile into the intestine and thereby the enterohepatic circulation. Normally, the pool and circulation of BAs 
maintains a dynamic balance, while it would be disrupted by biliary intervention or in pathological condition.

Gallbladder was considered merely to concentrate and store bile by absorbing water and ions previously, while recent studies showed that cholecystectomy would affect the metabolism of BAs. Several studies have demonstrated that TBA levels increase markedly after cholecystectomy [8, 22], while other studies showed BAs remained unchanged [9] or decreased [12]. In our study TBA level increased significantly after LC, the underlying mechanism was still not elucidated. Removal of gallbladder leads BAs to continuously secret into duodenum, theoretically faster circulated BAs would inhibit the cholesterol 7ahydroxylase in the liver, the rate-limiting enzyme for bile formation, thereby reduce the bile synthesis. However, increased TBA level were observed in most studies or at least unchanged. Increased bile loss in feces due to the enhanced enterohepatic circling after cholecystectomy have been demonstrated [13], thereby the bile synthesis compensatory increased. We suspected massive loss of bile lead to an excessive bile synthesis, it may play a predominant role for the bile synthesis, but further studies were still need to be performed.

In recent years, increasing attention has been paid to the role of BAs as a signaling molecular, that regulate various hormones and receptors and modulate whole-body metabolic homeostasis [23]. The most widely studied receptors are the farnesoid $X$ receptor (FXR) and the membrane $G$ protein-coupled $B A$ receptors (GPBAR1/TGR5) [24]. FXR stimulates the secretion of fibroblast growth factor 19 into the portal circulation and activates its fibroblast growth factor 4 liver receptor, leading to decreased gluconeogenesis glycemia and improved insulin sensitivity and glucose and lipid metabolism in diabetes $[25,26]$. BAs activate TGR5, which is expressed in enteroendocrine L cells and stimulates the secretion of glucagon-like peptide-1, thereby improving liver and pancreatic function, stimulating insulin secretion from $\beta$-cells, increasing insulin sensitivity and glucose tolerance [27].

Moreover, BAs are also involved in the energy expenditure, in line with previous studies, we found REE increased after cholecystectomy $[7,10]$. The activation of TGR5 by BAs induces thyroid hormone deiodinase type 2 , which converts the inactive thyroid hormone thyroxine to active triiodothyronine thereby increased energy expenditure [28]. Moreover, plasm BAs can directly promote heat production in brown adipose tissue and skeletal muscle, which were two of important organs for thermogenesis [29, 30]. Energy expenditure is also influenced by an interplay of BAs and intestinal microbiota. The level and composition of TBA affect the gut microbial community abundance and composition [31]. The gut microbiota can digest complex food components and produce signaling molecules, including short-chain fatty acids, lipopolysaccharides, and peptidoglycan etc. Such signaling molecules promoted energy intake, use, and expenditure [32].

Although studies reported glucose deteriorated in normal patients after LC [6,33], this may not be applied to the patients with T2DM due to the damaged metabolic regulation. Our study showed that glucose improved in patients with T2DM after LC,the total effective rate was $45 \%$, the level of FPG and A1C decreased compared to baseline. While there were no significant changes in food intake and body weight. 
Therefore, these improvements were unrelated to food intake and weight loss. Increased BAs may be responsible for the glucose improvement, according to abovementioned mechanism, BAs can directly or indirectly activate several gut hormones, thereby improved insulin resistant which was also confirmed by the estimation of HOMA-IR in present study. Moreover, the proportion of carbohydrates in the REE increased after LC while that of fat decreased. Carbohydrates are the most important source of energy, and approximately $50-70 \%$ of energy used in the body comes from the breakdown of blood glucose. Therefore, decrease in glucose level also related to the increased REE level.

With the improvement in glucose metabolism, dyslipidemia was also alleviated, HDL-C levels were elevated after surgery, TC and LDL-C concentrations were significantly decreased. Dyslipidemia is an important component of diabetes and has received much attention in recent years, but the underlying pathophysiology is complex and still not well understood [34]. Insulin resistance is believed to be the main trigger for diabetic dyslipidemia. Insulin is involved in the synthesis and secretion of lipoprotein, suppresses lipolysis in adipose tissues, regulates the amount of circulating free fatty acids, and inhibits the transcription of microsomal triglyceride transfer protein in the liver, which mediates the transfer of triglycerides to nascent apolipoprotein $B$, the predominant surface protein of very-low-density lipoprotein. A reduction in insulin resistance positively regulates this process, helping lower the lipoprotein. Therefore, the reduction in insulin resistance may lead to the improvement of dyslipidemia which was confirmed in our study. Additionally, beneficial changes of lipids metabolism were more likely occurred in dyslipidemic patient after biliary interventions, this had also been proved in several previous studies $[13,35]$, but this effects were not found in patients with normal lipids metabolism. Nevertheless, the underlying mechanism of this difference between dyslipidemic and non-dyslipidemic patients was still unclear.

There are a few limitations of this study. A randomized study needed to be performed to confirm our results, and the effects on gut hormones also need to be investigated. Nevertheless, the results of our study show that the level of TBA and REE increased after cholecystectomy in patients with T2DM, and indicate the possible role of the BAs and REE in remission of T2DM which may be a potential possibility for treatment of metabolic diseases.

\section{Conclusions}

The level of REE and TBA increased after LC in patients with T2DM, the glucose and lipid metabolism improved.

\section{Abbreviations}

\section{T2DM}

Type 2 diabetes mellitus

\section{LC}

Laparoscopic cholecystectomy

REE 
Resting energy expenditure

BMI

body mass index

FPG

Fasting plasma glucose

A1C

Hemoglobin A1C

TBA

Total bile acids

TC

Total cholesterol

TG

Triglyceride

HDL-C

High-density lipoprotein cholesterol

LDL-C

Low-density lipoprotein cholesterol

HOMA-IR

Homeostasis model assessment-insulin resistance

HOMA- $\beta$

Homeostasis model assessment - beta cell function

FXR

Farnesoid $\mathrm{X}$ receptor

GPBAR1/TGR5

G protein-coupled BA receptors

\section{Declarations}

\section{Acknowledgments}

We thank the American Journal Experts for polishing the language.

\section{Funding}

This study was funded by National Natural Science Foundation of China (81970763), CAMS Innovation Fund for Medical Sciences (CIFMS, 2017-I2M-4-003), and Program Focus Health of Liver and Gallbladder in Elder (ZYJ201912).

\section{Authors' contributions}

CWJ and HXD conceived and designed the experiments, YHX analyzed the date and wrote the original draft, QQ, ZN, DLB and ZSN revised the draft, all authors have read and approved the final manuscript. 
Availability of data and materials

The datasets generated and/or analysed during the current study are not publicly available due to personal data protection legislation but are available from the corresponding author on reasonable request.

\section{Ethics approval and consent to participate}

The study was approved by the Ethics Committee of PUMCH at the Chinese Academy of Medical Sciences and Peking Union Medical College. Written informed consent was obtained from all participants for this manuscript.

\section{Consent for publication}

Not applicable.

\section{Competing interests}

The authors declare that they have no conflicts of interest to disclose.

\section{References}

1. Matsuzaka T, Shimano H. A new perspective on type 2 diabetes, dyslipidemia, and non-alcoholic fatty liver disease. J Diabetes Investig 2020.

2. Shrestha SS, Honeycutt AA, Yang W, et al. Economic Costs Attributable to Diabetes in Each U.S. State. Diabetes Care. 2018;41:2526-34.

3. Zheng Y, Ley SH, Hu FB. Global aetiology and epidemiology of type 2 diabetes mellitus and its complications. Nat Rev Endocrinol. 2018;14:88-98.

4. Lammert F, Gurusamy K, Ko CW, et al. Gallstones Nat Rev Dis Primers. 2016;2:16024.

5. Shim P, Choi D, Park Y. Association of Blood Fatty Acid Composition and Dietary Pattern with the Risk of Non-Alcoholic Fatty Liver Disease in Patients Who Underwent Cholecystectomy. Ann Nutr Metab. 2017;70:303-11.

6. Shen C, Wu X, Xu C, Yu C, Chen P, Li Y. Association of cholecystectomy with metabolic syndrome in a Chinese population. PLoS One. 2014;9:e88189.

7. Cortés V, Amigo L, Zanlungo S, et al. Metabolic effects of cholecystectomy: gallbladder ablation increases basal metabolic rate through G-protein coupled bile acid receptor Gpbar1-dependent mechanisms in mice. PLoS One. 2015;10:e0118478.

8. Barrera F, Azócar L, Molina H, et al. Effect of cholecystectomy on bile acid synthesis and circulating levels of fibroblast growth factor 19. Ann Hepatol. 2015;14:710-21.

9. Amigo L, Husche $C$, Zanlungo S, et al. Cholecystectomy increases hepatic triglyceride content and very-low-density lipoproteins production in mice. Liver Int. 2011;31:52-64. 
10. Luo K, Li JS, Li LT, Wang KH, Shun JM. Operative stress response and energy metabolism after laparoscopic cholecystectomy compared to open surgery. World J Gastroenterol. 2003;9:847-50.

11. Kullak-Ublick GA, Paumgartner G, Berr F. Long-term effects of cholecystectomy on bile acid metabolism. Hepatology. 1995;21:41-5.

12. Zhang F, Qin H, Zhao Y, et al. Effect of cholecystectomy on bile acids as well as relevant enzymes and transporters in mice: Implication for pharmacokinetic changes of rifampicin. Eur J Pharm Sci. 2017;96:141-53.

13. Cholecystectomy and Biliary Sphincterotomy Increase Fecal. Bile Loss and Improve Lipid Profle in Dyslipidemia.

14. Diagnosis and classification of diabetes mellitus. Diabetes Care. 2010;33(Suppl 1):62-9.

15. Ata N, Kucukazman M, Yavuz B, et al. The metabolic syndrome is associated with complicated gallstone disease. Can J Gastroenterol. 2011;25:274-6.

16. Yudkin JS, Juhan-Vague I, Hawe E, et al. Low-grade inflammation may play a role in the etiology of the metabolic syndrome in patients with coronary heart disease: the HIFMECH study. Metabolism. 2004;53:852-7.

17. The Diabetes Prevention Program (DPP). description of lifestyle intervention. Diabetes Care. 2002;25:2165-71.

18. Zachariah PJ, Chen CY, Lee WJ, et al. Compared to Sleeve Gastrectomy, Duodenal-Jejunal Bypass with Sleeve Gastrectomy Gives Better Glycemic Control in T2DM Patients, with a Lower $\beta$-Cell Response and Similar Appetite Sensations: Mixed-Meal Study. Obes Surg. 2016;26:2862-72.

19. Buse JB, Caprio S, Cefalu WT, et al. How do we define cure of diabetes. Diabetes Care. 2009;32:2133-5.

20. Monte MJ, Marin JJ, Antelo A, Vazquez-Tato J. Bile acids: chemistry, physiology, and pathophysiology. World J Gastroenterol. 2009;15:804-16.

21. Fan M, Wang X, Xu G, Yan Q, Huang W. Bile acid signaling and liver regeneration. Biochim Biophys Acta. 2015;1849:196-200.

22. Zhang F, Duan Y, Xi L, et al. The influences of cholecystectomy on the circadian rhythms of bile acids as well as the enterohepatic transporters and enzymes systems in mice. Chronobiol Int. 2018;35:673-90.

23. Li T, Chiang JY. Bile acid signaling in metabolic disease and drug therapy. Pharmacol Rev. 2014;66:948-83.

24. Rajani C, Jia W. Bile acids and their effects on diabetes. Front Med. 2018;12:608-23.

25. Zhang Y, Lee FY, Barrera G, et al. Activation of the nuclear receptor FXR improves hyperglycemia and hyperlipidemia in diabetic mice. Proc Natl Acad Sci U S A. 2006;103:1006-11.

26. DePaoli AM, Zhou M, Kaplan DD, et al. FGF19 Analog as a Surgical Factor Mimetic That Contributes to Metabolic Effects Beyond Glucose Homeostasis. Diabetes. 2019;68:1315-28. 
27. Ding L, Sousa KM, Jin L, et al. Vertical sleeve gastrectomy activates GPBAR-1/TGR5 to sustain weight loss, improve fatty liver, and remit insulin resistance in mice. Hepatology. 2016;64:760-73.

28. Watanabe M, Houten SM, Mataki $C$, et al. Bile acids induce energy expenditure by promoting intracellular thyroid hormone activation. Nature. 2006;439:484-9.

29. Contreras C, Nogueiras R, Diéguez C, Medina-Gómez G, López M. Hypothalamus and thermogenesis: Heating the BAT, browning the WAT. Mol Cell Endocrinol. 2016;438:107-15.

30. Broeders EP, Nascimento EB, Havekes B, et al. The Bile Acid Chenodeoxycholic Acid Increases Human Brown Adipose Tissue Activity. Cell Metab. 2015;22:418-26.

31. Staley C, Weingarden AR, Khoruts A, Sadowsky MJ. Interaction of gut microbiota with bile acid metabolism and its influence on disease states. Appl Microbiol Biotechnol. 2017;101:47-64.

32. Nieuwdorp M, Gilijamse PW, Pai N, Kaplan LM. Role of the microbiome in energy regulation and metabolism. Gastroenterology. 2014;146:1525-33.

33. Sonne DP, Hare KJ, Martens P, et al. Postprandial gut hormone responses and glucose metabolism in cholecystectomized patients. Am J Physiol Gastrointest Liver Physiol. 2013;304:G413-9.

34. Wu L, Parhofer KG. Diabetic dyslipidemia. Metabolism. 2014;63:1469-79.

35. Malik AA, Wani ML, Tak SI, Irshad I, Ul-Hassan N. Association of dyslipidaemia with cholilithiasis and effect of cholecystectomy on the same. Int J Surg. 2011;9:641-2.

\section{Figures}


A

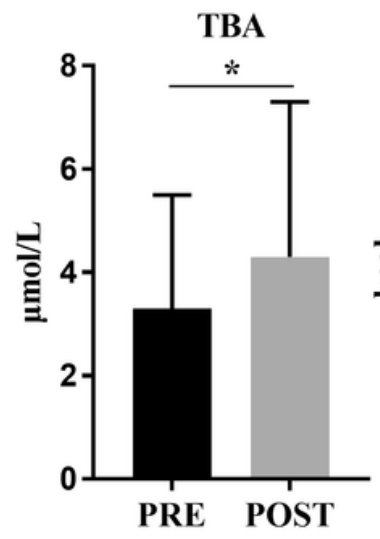

$\mathbf{E}$

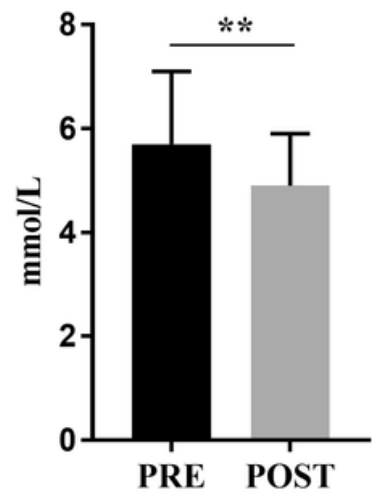

B

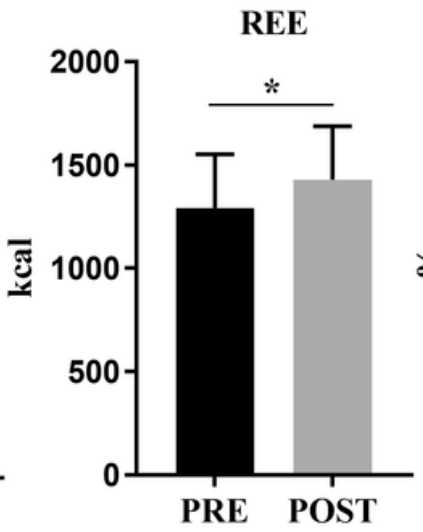

$\mathbf{F}$
C

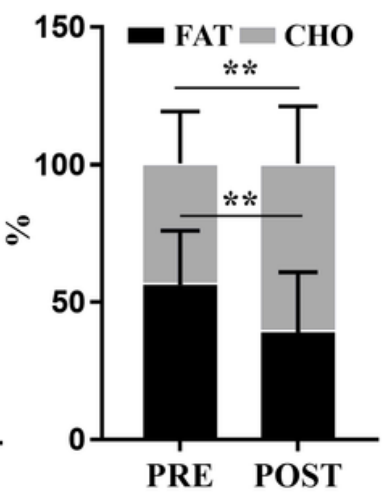

G
D

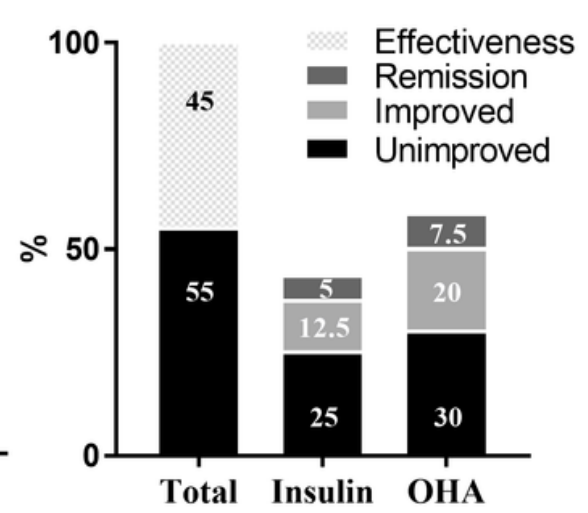

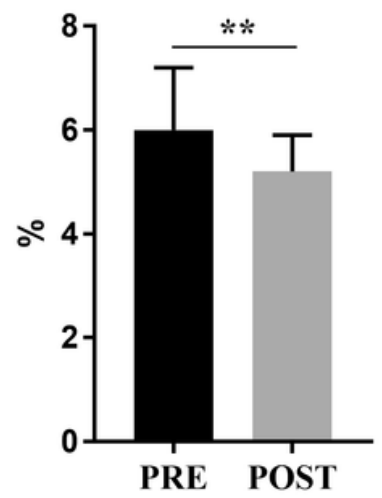

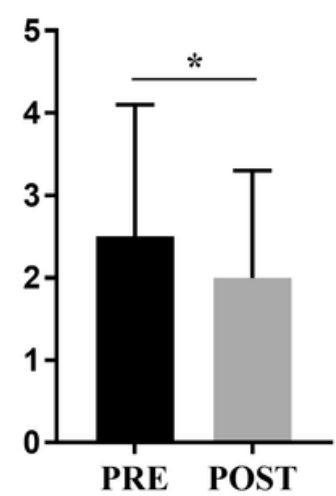

$\mathbf{H}$

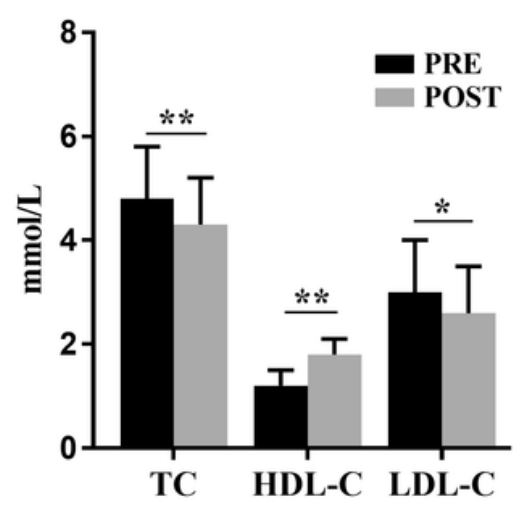

Figure 1

Postoperative characteristics and changes in metabolism of energy, glucose, and lipid after LC. The level of TBA (A) and REE (B) increased after surgery, consumption of carbohydrate increased while fat consumption decreased (C). Dosage of antidiabetic medication drugs decreased in partial patients after LC (D), the level of FPG (E), A1C (F) and HOMA-IR (G) decreased 6 months after LC. For lipid metabolism (H), TC and LDL-C level decreased after surgery, HDL-C level increased. PRE, preoperative; POST, postoperative; TBA, total bile acids; REE, resting energy expenditure; $\mathrm{CHO}$, carbohydrate, $\mathrm{OHA}$, oral hypoglycemic agents; FPG, fasting plasma glucose; A1C, hemoglobin A1c; HOMA-IR, homeostasis model assessment-insulin resistance; TC, total cholesterol; HDL-C, high-density lipoprotein cholesterol; LDL-C, low density lipoprotein cholesterol. Data are shown as the mean $\pm S D$, * indicates $P<0.05$, ** indicates $P<$ 0.01, compared between preoperative and postoperative.

\section{Supplementary Files}

This is a list of supplementary files associated with this preprint. Click to download.

- CONSORTChecklist.doc 